\title{
IMPLEMENTASI ALGORITMA C4.5 UNTUK MENENTUKAN CALON DEBITUR DENGAN MENGUKUR TINGKAT RISIKO KREDIT PADA BANK BRI CABANG CURUP
}

\author{
Muhammad Husni Rifqo ${ }^{1}$, Taufik Arzi ${ }^{2}$ \\ ${ }^{1,2}$ Program Studi Informatika, Fakultas Teknik, Universitas Muhammadiyah Bengkulu \\ Jl. Bali PO BOX 118. Telp (0736) 227665, Fax (0736) 26161, Bengkulu 38119 \\ ${ }^{1}$ kokoahzani@gmail.com \\ 2arzitaufik@gmail.com
}

Abstrak: Perbankan adalah salah satu sumber dana bagi masyarakat perorangan atau badan usaha untuk memenuhi kebutuhan konsumsinya seperti kebutuhan untuk membeli rumah, mobil atau motor ataupun untuk meningkatkan produksi usahanya mengingat modal yang dimiliki perusahaaan ataupun perorangan tidak cukup untuk mendukung peningkatan usahanya. Risiko perkreditan yang terutama bagi bank adalah bahwa kredit menjadi macet dalam arti bank tidak lagi atau tidak teratur dalam menerima bunga dan angsuran pelunasan kredit. Hal tersebut sangat merugikan pihak bank karena tidak lagi menerima bunga. Algoritma C4.5 bisa digunakan untuk analisa yang dilakukan oleh analis kredit. Penerapan algoritma dalam aplikasi ini bertujuan untuk membuat suatu sistem pendukung keputusan yang dapat memberikan suatu alternatif keputusan bagi para pengambil keputusan dalam menentukan tingkat risiko pemberian kredit.

Kata Kunci : perbankan, risiko kredit, algoritma C4.5.

Abstract: Banking is one source of funds for the community individual or business entity to meet its consumption needs such as the need to buy a house, a car or a motorcycle, or to increase the production of its business given capital owned firms or individuals is not enough to support the increased efforts. Credit risk is primarily for banks is that credit to be jammed in the sense that banks are no longer or irregular in receiving repayment of interest and installment loans. This is very detrimental to the bank because it no longer receives interest. C4.5 algorithms can be used for analysis by credit analysts. The application of the algorithms in this application aims to create a decision support system that can provide an alternative decision for decision makers in determine the risk level of the loan.

Keywords: Banking, credit risk, the algorithm C4.5.

\section{PENDAHULUAN}

Bank merupakan lembaga keuangan bekerja berdasar kepercayaan. Dalam kegiatan operasionalnya, bank menghimpun dana dari masyarakat dalam bentuk giro, tabungan maupun

ejournal.unib.ac.id deposito dan menyalurkan kembali dana tersebut kepada masyarakat dalam bentuk kredit.

Berdasarkan Undang-Undang Republik Indonesia Nomor 10 tahun 1998 tentang Perubahan atas Undang-Undang Nomor 7 Tahun 1992 tentang Perbankan, Bank disebutkan sebagai badan usaha yang menghimpun dana dari masyarakat dalam bentuk simpanan dan menyalurkannya kepada masyarakat dalam bentuk kredit dan atau bentuk-bentuk lainnya dalam rangka meningkatkan taraf hidup masyarakat.

Kegiatan kredit pada perusahaan sangat dipengaruhi oleh banyak faktor baik dari dalam maupun dari luar, salah satu faktor penghambatnya adalah masalah kredit yang diajukan oleh calon pelanggan memiliki risiko. Risiko kredit adalah kemungkinan penurunan hasil kredit dari tindakan peminjam yang mempunyai reputasi yang buruk [1], risiko kredit mengancam sistem ekonomi 
perusahaan [2]. Oleh karena itu dibutuhkan seorang pengambil keputusan pada suatu perusahaan yang mampu mengambil keputusan yang tepat dalam menganalisa kredit.

Risiko perkreditan yang terutama bagi bank adalah bahwa kredit menjadi macet dalam arti bank tidak lagi atau tidak teratur dalam menerima bunga dan angsuran pelunasan kredit. Hal tersebut sangat merugikan pihak bank karena tidak lagi menerima bunga.

Penilaian kredit menjadi isu yang sangat penting dalam pertumbuhan industri kredit yang sangat cepat. Keuntungan menggunakan model penilaian kredit [3] adalah:

1. Mengurangi biaya analisis kredit

2. Memungkinkan keputusan kredit lebih cepat dan

3. Mengurangi risiko kredit

Proses untuk mencari atau memperoleh informasi dengan menggunakan teknik tertentu disebut dengan Data Mining [4].

Salah satu metode yang sering digunakan dalam data mining adalah metode klasifikasi menggunakan algoritma C4.5. Algoritma C4.5 merupakan salah satu algoritma yang menggunakan metode klasifikasi dalam membangun pohon keputusan, yaitu sebuah struktur yang dapat digunakan untuk membagi kumpulan data yang besar menjadi himpunanhimpunan yang lebih kecil dengan menerapkan serangkaian aturan keputusan.

Perusahaan sangat membutuhkan teknik prediksi dalam mengambil suatu keputusan kredit, banyak penelitian yang dilakukan untuk permasalahan risiko kredit dengan menggunakan bermacam metode, misalnya metode neural network, Classification And Regression Tree (CART), Naive Bayes, C4.5, Support Vector
Machine (SVM), dan metode lain, metode itu dipilih sesuai dengan data dan tujuannya.

Yu and Wang [5] megusulkan algoritma penilaian kredit dengan menggunakan Genetic Algorithm berbasis Bayesian Network, hasil eksperimen terbagi dua yaitu untuk menguji kinerja metode yang diusulkan dan yang kedua adalah membandingkan kinerja dengan metode yang lain. Hasilnya metode Naive Bayes berbasis GA memiliki persentase yang lebih baik dalam hal correctly predicted 18,992 dan correct rate $53.23 \%$.

Setiap metode data mining yang digunakan memiliki kelebihan masing-masing, oleh karena itu analisa kredit sangat penting dalam perusahaan kredit.

Berdasarkan latar belakang diatas, masalah dalam penelitian ini adalah bagaimana menerapkan algoritma C4.5 untuk menentukan calon debitur dengan mengukur tingkat risiko pengkreditan pada bank BRI agar pihak bank tidak mengalami kerugian dengan macetnya pelunasan kredit pinjaman.

\section{LANDASAN TEORI}

\subsection{Algoritma}

Algoritma bisa berarti urutan atau langkahlangkah secara logis atau matematis dalam menyelsaikan masalah tertentu.

\subsection{Algoritma C4.5}

Algoritma C4.5 adalah algoritma pohon keputusan yang terkenal. Algoritma C4.5 pertama sekali diperkenalkan oleh Quinlan (1996) sebagai versi perbaikan ID3.

Algoritma C4.5 menggunakan konsep information gain atau entropy reduction untuk memilih pembagian yang optimal [6]. 
Secara umum algoritma C4.5 untuk lembaga keuangan dengan pihak lain yang membangun keputusan adalah sebagai berikut :
a. Pilih atribut sebagai akar
b. Buat cabang untuk tiap-tiap nilai bunga.

c. Bagi kasus dalam cabang

d. Ulangi proses untuk setiap cabang sampai kasus pada cabang memiliki kelas yang sama.

Untuk memilih atribut sebagai akar, didasarkan pada nilai gain tertinggi dari atributatribut yang ada. Untuk menghitung gain digunakan rumus tertera dalam persamaan (1) berikut :

$\operatorname{Gain}(S, A)=\operatorname{Entropy}(S)-\sum_{i=1}^{n} \frac{|S i|}{|S|} * \operatorname{Entropy}(S i)$ (1) Keterangan:

$S \quad$ : Himpunan kasus

$A \quad$ : Atribut

$N$ : Jumlah partisi atribut $A$

$|S i|$ : jumlah kasus pada partisi ke- $i$

$|S|$ : Jumlah kasus dalam $S$

Sedangkan, penghitungan nilai entropy dapat dilihat pada persamaan (2) berikut.

$$
\operatorname{Entropy}(S)=\sum_{i=1}^{n}-p i * \log _{2} p i
$$

Keterangan:

$S \quad$ : Himpunan kasus

A : Fitur

$n \quad$ : jumlah partisi $S$

$P i \quad$ : proporsi dari $S i$ terhadap $S$

Dalam Penghitungan $\log 2$ pada rumus C4.5 menggunakan aturan perhitungan pada persamaan (3) berikut:

$$
\log 2(X)=\frac{\operatorname{In}(x)}{\operatorname{In} 2}
$$

\subsection{Kredit}

Undang-undang Republik Indonesia No.10 Tahun 1998 [7] menjelaskan kredit adalah penyediaan uang atau tagihan yang dapat dipersamakan dengan itu, berdasarkan persetujuan atau kesepakatan pinjam meminjam antara

mewajibkan pihak peminjam melunasi utangnya setelah jangka waktu tertentu dengan pemberian

Pada umumnya setiap bank menggunakan kriteria 5C dalam menentukan kelayakan pemberian kredit kepada calon debitur yaitu: character, capacity, capital, collateral, dan condition of economi.

\subsection{Risiko Kredit}

Risiko kredit adalah kemungkinan penurunan hasil kredit dari tindakan peminjam yang mempunyai reputasi yang buruk [8]. Salah satu risiko yang dihadapi bank dalam menjalankan bisnisnya adalah risiko likuiditas. Risiko kredit bisa diminimalisasi oleh perushaan dengan menganalisa aplikasi dari pemohon kredit dengan tepat dan akurat, pengambilan keputusan yang kurang tepat berdampak pada kegiatan perkreditan diperusahaan tersebut.

\subsection{Sekilas tentang BRI Cabang Curup}

Bank Rakyat Indonesia (BRI) adalah salah satu bank milik pemerintah yang terbesar di Indonesia. Pada awalnya BRI didirikan di Purwokerto, Jawa Tengah oleh Raden Bei Aria Wirjaatmadja dengan nama De Poerwokertosche Hulp en Spaarbank der Inlandsche Hoofden atau "Bank Bantuan dan Simpanan Milik Kaum Priyayi Purwokerto", suatu lembaga keuangan yang melayani orang-orang berkebangsaan Indonesia (pribumi). Lembaga tersebut berdiri tanggal 16 Desember 1895, yang kemudian dijadikan sebagai hari kelahiran BRI.

Bank Rakyat Indonesia Cabang Curup beralamat di Jl. Merdeka No. 49 Curup, Kabupaten Rejang Lebong. Bank Rakyat Indonesia Cabang 
Jurnal Pseudocode, Volume III Nomor 2, September 2016, ISSN 2355-5920

Curup membawahi 11 BRI unit, 5 teras BRI, dan 1 teras keliling.

\section{METODE PENELITIAN}

Model pengembangan sistem yang digunakan adalah model Incremental karena model ini cocok untuk proyek dengan skala yang kecil. Model Incremental dalam rekayasa perangkat lunak menerapkan rekayasa perangkat lunak perbagian, hingga menghasilkan perangkat lunak yang lengkap. Proses membangun berhenti jika produk telah mencapai seluruh fungsi yang diharapkan. Model ini terdiri dari proses Analisa, Desain, Kode dan Pengujian/test pada Gambar 1.

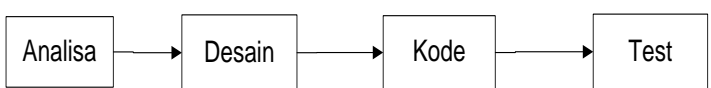

Gambar 1. Model Incremental

\section{HASIL DAN PEMBAHASAN}

4.1 Implementasi Algoritma C4.5

Pembentukan pohon keputusan algoritma c4.5 dengan perhitungan 30 data penelitian.

Tabel 1. Data Penelitian

\begin{tabular}{|r|l|l|l|l|}
\hline No & Nama & $\begin{array}{c}\text { Penilaian } \\
\text { masyarakat }\end{array}$ & $\begin{array}{c}\text { Sikap calon } \\
\text { debitur }\end{array}$ & Lama usaha \\
\hline 1 & 01 & baik & kooperatif & $>2$ tahun \\
\hline 2 & 02 & baik & kooperatif & $>2$ tahun \\
\hline 3 & 03 & baik & kooperatif & $<2$ tahun \\
\hline 4 & 04 & cukup & kooperatif & $>2$ tahun \\
\hline 5 & 05 & baik & $\begin{array}{l}\text { kurang } \\
\text { kooperatif }\end{array}$ & 2 tahun \\
\hline 6 & 06 & kurang & $\begin{array}{l}\text { kurang } \\
\text { kooperatif }\end{array}$ & $>2$ tahun \\
\hline 7 & 07 & cukup & kooperatif & 2 tahun \\
\hline 8 & 08 & baik & kooperatif & $>2$ tahun \\
\hline 9 & 09 & baik & Kooperatif & $<2$ tahun \\
\hline 10 & 10 & Baik & Kooperatif & $<2$ tahun \\
\hline 11 & 11 & Cukup & Kooperatif & $>2$ tahun \\
\hline 12 & 12 & Baik & $\begin{array}{l}\text { kurang } \\
\text { kooperatif }\end{array}$ & $<2$ tahun \\
\hline 13 & 13 & Baik & $\begin{array}{l}\text { kurang } \\
\text { kooperatif }\end{array}$ & $>2$ tahun \\
\hline 14 & 14 & Baik & Kooperatif & 2 tahun \\
\hline
\end{tabular}

\begin{tabular}{|c|c|c|c|c|}
\hline 15 & 15 & Baik & Kooperatif & 2 tahun \\
\hline 16 & 16 & Baik & Kooperatif & 2 tahun \\
\hline 17 & 17 & Cukup & Kooperatif & 2 tahun \\
\hline 18 & 18 & cukup & Kooperatif & 2 tahun \\
\hline 19 & 19 & kurang & Kooperatif & 2 tahun \\
\hline 20 & 20 & cukup & $\begin{array}{l}\text { kurang } \\
\text { kooperatif }\end{array}$ & $>2$ tahun \\
\hline 21 & 21 & cukup & $\begin{array}{l}\text { kurang } \\
\text { kooperatif }\end{array}$ & $>2$ tahun \\
\hline 22 & 22 & kurang & $\begin{array}{l}\text { kurang } \\
\text { kooperatif }\end{array}$ & 2 tahun \\
\hline 23 & 23 & cukup & Kooperatif & $>2$ tahun \\
\hline 24 & 24 & kurang & Kooperatif & 2 tahun \\
\hline 25 & 25 & baik & $\begin{array}{l}\text { kurang } \\
\text { kooperatif }\end{array}$ & $>2$ tahun \\
\hline 26 & 26 & cukup & Kooperatif & 2 tahun \\
\hline 27 & 27 & kurang & Kooperatif & $>2$ tahun \\
\hline 28 & 28 & kurang & Kooperatif & $>2$ tahun \\
\hline 29 & 29 & cukup & $\begin{array}{l}\text { kurang } \\
\text { kooperatif }\end{array}$ & $>2$ tahun \\
\hline 30 & 30 & cukup & $\begin{array}{l}\text { kurang } \\
\text { kooperatif }\end{array}$ & $>2$ tahun \\
\hline
\end{tabular}

Tabel 2. Kriteria 1 Data Penelitian

\begin{tabular}{|c|c|c|c|c|}
\hline $\begin{array}{c}\text { Memiliki } \\
\text { catatan } \\
\text { usaha }\end{array}$ & $\begin{array}{c}\text { Jumlah } \\
\text { pelanggan }\end{array}$ & Pendapatan & $\begin{array}{l}\text { Jumlah } \\
\text { pesaing }\end{array}$ & $\begin{array}{c}\text { Aset } \\
\text { usaha }\end{array}$ \\
\hline Ya & $>100$ & $>3$ juta & $\begin{array}{l}\text { cukup } \\
\text { banyak }\end{array}$ & $\begin{array}{l}<\text { jumlah } \\
\text { pinjaman }\end{array}$ \\
\hline Ya & $>100$ & $>3$ juta & $\begin{array}{l}\text { cukup } \\
\text { banyak }\end{array}$ & $\begin{array}{l}<\text { jumlah } \\
\text { pinjaman }\end{array}$ \\
\hline Tidak & $50-100$ & 2-3 juta & $\begin{array}{l}\text { cukup } \\
\text { banyak }\end{array}$ & $\begin{array}{c}=\text { jumlah } \\
\text { pinjaman }\end{array}$ \\
\hline $\mathrm{Ya}$ & $50-100$ & 2-3 juta & $\begin{array}{l}\text { cukup } \\
\text { banyak }\end{array}$ & $\begin{array}{l}>\text { jumlah } \\
\text { pinjaman }\end{array}$ \\
\hline Tidak & $50-100$ & 1-2 juta & $\begin{array}{l}\text { sangat } \\
\text { banyak }\end{array}$ & $\begin{array}{l}<\text { jumlah } \\
\text { pinjaman }\end{array}$ \\
\hline $\mathrm{Ya}$ & $50-100$ & 1-2 juta & $\begin{array}{l}\text { sangat } \\
\text { banyak }\end{array}$ & $\begin{array}{l}<\text { jumlah } \\
\text { pinjaman }\end{array}$ \\
\hline $\mathrm{Ya}$ & $50-100$ & $>3$ juta & banyak & $\begin{array}{l}<\text { jumlah } \\
\text { pinjaman }\end{array}$ \\
\hline $\mathrm{Ya}$ & $>100$ & $>3$ juta & $\begin{array}{l}\text { cukup } \\
\text { banyak }\end{array}$ & $\begin{array}{l}\text { > jumlah } \\
\text { pinjaman }\end{array}$ \\
\hline $\mathrm{Ya}$ & 50-100 & 2-3 juta & $\begin{array}{l}\text { cukup } \\
\text { banyak }\end{array}$ & $\begin{array}{l}\text { > jumlah } \\
\text { pinjaman }\end{array}$ \\
\hline $\mathrm{Ya}$ & $50-100$ & $>3$ juta & $\begin{array}{l}\text { cukup } \\
\text { banyak }\end{array}$ & $\begin{array}{l}<\text { jumlah } \\
\text { pinjaman }\end{array}$ \\
\hline $\mathrm{Ya}$ & $>100$ & $>3$ juta & banyak & $\begin{array}{l}>\text { jumlah } \\
\text { pinjaman }\end{array}$ \\
\hline Tidak & $<50$ & 2-3 juta & $\begin{array}{l}\text { sangat } \\
\text { banyak }\end{array}$ & $\begin{array}{l}<\text { jumlah } \\
\text { pinjaman }\end{array}$ \\
\hline $\mathrm{Ya}$ & $50-100$ & 2-3 juta & $\begin{array}{l}\text { cukup } \\
\text { banyak }\end{array}$ & $\begin{array}{l}>\text { jumlah } \\
\text { pinjaman }\end{array}$ \\
\hline Ya & $>100$ & $>3$ juta & banyak & $\begin{array}{l}>\text { jumlah } \\
\text { pinjaman }\end{array}$ \\
\hline Tidak & $50-100$ & $>3$ juta & $\begin{array}{l}\text { cukup } \\
\text { banyak }\end{array}$ & $\begin{array}{l}<\text { jumlah } \\
\text { pinjaman }\end{array}$ \\
\hline Ya & $50-100$ & 2-3 juta & $\begin{array}{l}\text { sangat } \\
\text { banyak }\end{array}$ & $\begin{array}{l}>\text { jumlah } \\
\text { pinjaman }\end{array}$ \\
\hline Ya & $>100$ & $>3$ juta & $\begin{array}{l}\text { sangat } \\
\text { banyak }\end{array}$ & $\begin{array}{l}>\text { jumlah } \\
\text { pinjaman }\end{array}$ \\
\hline
\end{tabular}


Jurnal Pseudocode, Volume III Nomor 2, September 2016, ISSN 2355-5920

\begin{tabular}{|l|l|l|l|l|}
\hline Ya & $>100$ & $>3$ juta & $\begin{array}{l}\text { cukup } \\
\text { banyak }\end{array}$ & $\begin{array}{l}>\text { jumlah } \\
\text { pinjaman }\end{array}$ \\
\hline Ya & $50-100$ & 2-3 juta & banyak & $\begin{array}{l}>\text { jumlah } \\
\text { pinjaman }\end{array}$ \\
\hline Tidak & $<50$ & $<1$ juta & $\begin{array}{l}\text { cukup } \\
\text { banyak }\end{array}$ & $\begin{array}{l}>\text { jumlah } \\
\text { pinjaman }\end{array}$ \\
\hline Tidak & $>100$ & $>3$ juta & $\begin{array}{l}\text { sangat } \\
\text { banyak }\end{array}$ & $\begin{array}{l}\text { = jumlah } \\
\text { pinjaman }\end{array}$ \\
\hline Ya & $50-100$ & $>3$ juta & $\begin{array}{l}\text { sangat } \\
\text { banyak }\end{array}$ & $\begin{array}{l}\text { = jumlah } \\
\text { pinjaman }\end{array}$ \\
\hline Tidak & $50-100$ & $>3$ juta & $\begin{array}{l}\text { cukup } \\
\text { banyak }\end{array}$ & $\begin{array}{l}=\text { jumlah } \\
\text { pinjaman }\end{array}$ \\
\hline Ya & $50-100$ & $>3$ juta & $\begin{array}{l}\text { sangat } \\
\text { banyak }\end{array}$ & $\begin{array}{l}\text { = jumlah } \\
\text { pinjaman }\end{array}$ \\
\hline Tidak & $>100$ & $>3$ juta & $\begin{array}{l}\text { cukup } \\
\text { banyak }\end{array}$ & $\begin{array}{l}\text { = jumlah } \\
\text { pinjaman }\end{array}$ \\
\hline Tidak & $50-100$ & $2-3$ juta & $\begin{array}{l}\text { tidak } \\
\text { ada }\end{array}$ & $\begin{array}{l}<\text { jumlah } \\
\text { pinjaman }\end{array}$ \\
\hline Tidak & $50-100$ & $2-3$ juta & $\begin{array}{l}\text { sangat } \\
\text { banyak }\end{array}$ & $\begin{array}{l}<\text { jumlah } \\
\text { pinjaman }\end{array}$ \\
\hline Ya & $>100$ & $>3$ juta & $\begin{array}{l}\text { cukup } \\
\text { banyak }\end{array}$ & $\begin{array}{l}<\text { jumlah } \\
\text { pinjaman }\end{array}$ \\
\hline Ya & $50-100$ & $2-3$ juta & $\begin{array}{l}\text { cukup } \\
\text { banyak }\end{array}$ & $\begin{array}{l}=\text { jumlah } \\
\text { pinjaman }\end{array}$ \\
\hline Ya & $50-100$ & $2-3$ juta & banyak & $\begin{array}{l}>\text { jumlah } \\
\text { pinjaman }\end{array}$ \\
\hline
\end{tabular}

Tabel 3. Kriteria 2 Data Penelitian

\begin{tabular}{|c|c|c|c|}
\hline $\begin{array}{c}\text { Jangkauan } \\
\text { wilayah } \\
\text { pemasaran }\end{array}$ & $\begin{array}{c}\text { Jumlah } \\
\text { modal } \\
\text { usaha }\end{array}$ & $\begin{array}{l}\text { Memiliki } \\
\text { hutang } \\
\text { ditempat } \\
\text { lain }\end{array}$ & Hak milik jaminan \\
\hline Lokal & $>30 \%$ & Tidak & hak milik sendiri \\
\hline Regional & $>30 \%$ & Tidak & hak milik sendiri \\
\hline Lokal & $>30 \%$ & Tidak & hak milik bersama \\
\hline Lokal & $>30 \%$ & Tidak & hak milik sendiri \\
\hline Regional & $=30 \%$ & Tidak & hak milik sendiri \\
\hline Lokal & $>30 \%$ & $\mathrm{Ya}$ & hak milik sendiri \\
\hline Regional & $>30 \%$ & Tidak & hak milik bersama \\
\hline Lokal & $>30 \%$ & $\mathrm{Ya}$ & hak milik sendiri \\
\hline Lokal & $>30 \%$ & $\mathrm{Ya}$ & hak milik sendiri \\
\hline Regional & $>30 \%$ & Tidak & hak milik sendiri \\
\hline Lokal & $>30 \%$ & Tidak & hak milik bersama \\
\hline Lokal & $>30 \%$ & Ya & hak milik sendiri \\
\hline Regional & $>30 \%$ & Tidak & hak milik sendiri \\
\hline Regional & $>30 \%$ & Ya & hak milik sendiri \\
\hline Regional & $>30 \%$ & Tidak & hak milik sendiri \\
\hline Lokal & $>30 \%$ & Tidak & hak milik sendiri \\
\hline Lokal & $>30 \%$ & Ya & hak milik sendiri \\
\hline Lokal & $>30 \%$ & Tidak & hak milik sendiri \\
\hline Lokal & $>30 \%$ & Tidak & hak milik sendiri \\
\hline Regional & $>30 \%$ & Ya & hak milik sendiri \\
\hline Regional & $>30 \%$ & Tidak & hak milik sendiri \\
\hline Regional & $>30 \%$ & Tidak & hak milik sendiri \\
\hline
\end{tabular}

\begin{tabular}{|l|l|l|l|} 
Regional & $>30 \%$ & Tidak & hak milik sendiri \\
\hline Regional & $>30 \%$ & Ya & hak milik sendiri \\
\hline Regional & $>30 \%$ & Tidak & hak milik sendiri \\
\hline Regional & $\begin{array}{l}=30 \\
\%\end{array}$ & Ya & hak milik sendiri \\
\hline Lokal & $>30 \%$ & Tidak & hak milik sendiri \\
\hline Lokal & $>30 \%$ & Ya & hak milik sendiri \\
\hline Lokal & $>30 \%$ & Tidak & hak milik sendiri \\
\hline Lokal & $>30 \%$ & Tidak & hak milik sendiri \\
\hline
\end{tabular}

Tabel 4. Kriteria 3 Data Penelitian

\begin{tabular}{|c|c|c|c|c|}
\hline $\begin{array}{c}\text { Besarnya } \\
\text { taksasi } \\
\text { nilai } \\
\text { jaminan }\end{array}$ & $\begin{array}{c}\text { Jangka } \\
\text { waktu } \\
\text { pinjaman }\end{array}$ & $\begin{array}{c}\text { Larangan } \\
\text { pemerintah }\end{array}$ & $\begin{array}{c}\text { Pasang } \\
\text { surut harga } \\
\text { terhadap } \\
\text { usaha }\end{array}$ & Keputusan \\
\hline $\begin{array}{l}\text { jumlah } \\
\text { pinjaman }\end{array}$ & $\begin{array}{l}1-3 \\
\text { tahun }\end{array}$ & tidak ada & Terpengaruh & $\begin{array}{l}\text { Ya/ } \\
\text { rendah }\end{array}$ \\
\hline $\begin{array}{l}>\text { jumlah } \\
\text { pinjaman }\end{array}$ & $\begin{array}{l}1-3 \\
\text { tahun }\end{array}$ & tidak ada & Terpengaruh & $\begin{array}{l}\text { Ya/ } \\
\text { rendah }\end{array}$ \\
\hline $\begin{array}{l}>\text { jumlah } \\
\text { pinjaman }\end{array}$ & $\begin{array}{l}>3 \\
\text { tahun }\end{array}$ & tidak ada & Terpengaruh & $\begin{array}{l}\text { Ya/ } \\
\text { rendah }\end{array}$ \\
\hline $\begin{array}{l}>\text { jumlah } \\
\text { pinjaman }\end{array}$ & $\begin{array}{l}<1 \\
\text { tahun }\end{array}$ & tidak ada & Terpengaruh & $\begin{array}{l}\text { Ya / } \\
\text { rendah }\end{array}$ \\
\hline $\begin{array}{l}<\text { jumlah } \\
\text { pinjaman }\end{array}$ & $\begin{array}{l}>3 \\
\text { tahun }\end{array}$ & tidak ada & Terpengaruh & $\begin{array}{l}\text { Tidak } \\
\text { /tinggi }\end{array}$ \\
\hline $\begin{array}{l}<\text { jumlah } \\
\text { pinjaman }\end{array}$ & $\begin{array}{l}1-3 \\
\text { tahun }\end{array}$ & tidak ada & $\begin{array}{l}\text { sangat } \\
\text { terpengaruh }\end{array}$ & $\begin{array}{l}\text { Tidak } \\
\text { /tinggi }\end{array}$ \\
\hline $\begin{array}{l}>\text { jumlah } \\
\text { pinjaman }\end{array}$ & $\begin{array}{l}1-3 \\
\text { tahun }\end{array}$ & tidak ada & Terpengaruh & $\begin{array}{l}\text { Ya / } \\
\text { rendah }\end{array}$ \\
\hline $\begin{array}{l}>\text { jumlah } \\
\text { pinjaman }\end{array}$ & $\begin{array}{l}<1 \\
\text { tahun }\end{array}$ & tidak ada & Terpengaruh & $\begin{array}{l}\text { Ya / } \\
\text { rendah }\end{array}$ \\
\hline $\begin{array}{l}>\text { jumlah } \\
\text { pinjaman }\end{array}$ & $\begin{array}{l}1-3 \\
\text { tahun }\end{array}$ & tidak ada & Terpengaruh & $\begin{array}{l}\text { Ya / } \\
\text { rendah }\end{array}$ \\
\hline $\begin{array}{l}>\text { jumlah } \\
\text { pinjaman }\end{array}$ & $\begin{array}{l}<1 \\
\text { tahun }\end{array}$ & tidak ada & Terpengaruh & $\begin{array}{l}\text { Ya/ } \\
\text { rendah }\end{array}$ \\
\hline $\begin{array}{l}P \text { jumlah } \\
\text { pinjaman }\end{array}$ & $\begin{array}{l}1-3 \\
\text { tahun }\end{array}$ & tidak ada & Terpengaruh & $\begin{array}{l}\text { Ya/ } \\
\text { rendah }\end{array}$ \\
\hline $\begin{array}{l}<\text { jumlah } \\
\text { pinjaman }\end{array}$ & $\begin{array}{l}>3 \\
\text { tahun }\end{array}$ & tidak ada & $\begin{array}{l}\text { sangat } \\
\text { terpengaruh }\end{array}$ & $\begin{array}{l}\text { Tidak } \\
\text { /tinggi }\end{array}$ \\
\hline $\begin{array}{l}<\text { jumlah } \\
\text { pinjaman }\end{array}$ & $\begin{array}{l}>3 \\
\text { tahun }\end{array}$ & tidak ada & $\begin{array}{l}\text { tidak } \\
\text { terpengaruh }\end{array}$ & $\begin{array}{l}\text { Ya / } \\
\text { rendah }\end{array}$ \\
\hline $\begin{array}{l}<\text { jumlah } \\
\text { pinjaman }\end{array}$ & $\begin{array}{l}>3 \\
\text { tahun }\end{array}$ & tidak ada & Terpengaruh & $\begin{array}{l}\text { Ya / } \\
\text { rendah }\end{array}$ \\
\hline $\begin{array}{l}<\text { jumlah } \\
\text { pinjaman }\end{array}$ & $\begin{array}{l}<1 \\
\text { tahun }\end{array}$ & tidak ada & Terpengaruh & $\begin{array}{l}\text { Ya/ } \\
\text { rendah }\end{array}$ \\
\hline $\begin{array}{l}<\text { jumlah } \\
\text { pinjaman }\end{array}$ & $\begin{array}{l}>3 \\
\text { tahun }\end{array}$ & tidak ada & $\begin{array}{l}\text { sangat } \\
\text { terpengaruh }\end{array}$ & $\begin{array}{l}\text { Tidak } \\
\text { /tinggi }\end{array}$ \\
\hline $\begin{array}{l}=\text { jumlah } \\
\text { pinjaman }\end{array}$ & $\begin{array}{l}1-3 \\
\text { tahun }\end{array}$ & tidak ada & Terpengaruh & $\begin{array}{l}\text { Tidak } \\
\text { /tinggi } \\
\end{array}$ \\
\hline $\begin{array}{l}<\text { jumlah } \\
\text { pinjaman }\end{array}$ & $\begin{array}{l}>3 \\
\text { tahun }\end{array}$ & tidak ada & $\begin{array}{l}\text { sangat } \\
\text { terpengaruh }\end{array}$ & $\begin{array}{l}\text { Ya / } \\
\text { rendah }\end{array}$ \\
\hline $\begin{array}{l}<\text { jumlah } \\
\text { pinjaman }\end{array}$ & $\begin{array}{l}3 \\
\text { tahun }\end{array}$ & tidak ada & Terpengaruh & $\begin{array}{l}\text { Ya / } \\
\text { rendah }\end{array}$ \\
\hline $\begin{array}{l}<\text { jumlah } \\
\text { pinjaman }\end{array}$ & $\begin{array}{l}<1 \\
\text { tahun }\end{array}$ & tidak ada & $\begin{array}{l}\text { sangat } \\
\text { terpengaruh }\end{array}$ & $\begin{array}{l}\text { Tidak } \\
\text { /tinggi }\end{array}$ \\
\hline $\begin{array}{l}<\text { jumlah } \\
\text { pinjaman }\end{array}$ & $\begin{array}{l}1-3 \\
\text { tahun }\end{array}$ & tidak ada & Terpengaruh & $\begin{array}{l}\text { Tidak } \\
\text { /tinggi } \\
\end{array}$ \\
\hline $\begin{array}{l}<\text { jumlah } \\
\text { pinjaman }\end{array}$ & $\begin{array}{l}<1 \\
\text { tahun }\end{array}$ & tidak ada & $\begin{array}{l}\text { sangat } \\
\text { terpengaruh }\end{array}$ & $\begin{array}{l}\text { Tidak } \\
\text { /tinggi }\end{array}$ \\
\hline $\begin{array}{l}=\text { jumlah } \\
\text { pinjaman }\end{array}$ & $\begin{array}{l}<1 \\
\text { tahun }\end{array}$ & tidak ada & Terpengaruh & $\begin{array}{l}\text { Ya / } \\
\text { rendah }\end{array}$ \\
\hline $\begin{array}{l}<\text { jumlah } \\
\text { pinjaman }\end{array}$ & $\begin{array}{l}>3 \\
\text { tahun }\end{array}$ & tidak ada & Terpengaruh & $\begin{array}{l}\text { Tidak } \\
\text { /tinggi }\end{array}$ \\
\hline
\end{tabular}


Jurnal Pseudocode, Volume III Nomor 2, September 2016, ISSN 2355-5920

\begin{tabular}{|c|c|c|c|c|}
\hline $\begin{array}{l}=\text { jumlah } \\
\text { pinjaman }\end{array}$ & $\begin{array}{l}>3 \\
\text { tahun }\end{array}$ & tidak ada & \begin{tabular}{|l} 
sangat \\
terpengaruh
\end{tabular} & $\begin{array}{l}\text { Ya / } \\
\text { rendah }\end{array}$ \\
\hline $\begin{array}{l}<\text { jumlah } \\
\text { pinjaman }\end{array}$ & $\begin{array}{l}1-3 \\
\text { tahun }\end{array}$ & tidak ada & Terpengaruh & $\begin{array}{l}\text { Ya / } \\
\text { rendah }\end{array}$ \\
\hline $\begin{array}{l}<\text { jumlah } \\
\text { pinjaman }\end{array}$ & $\begin{array}{l}1-3 \\
\text { tahun }\end{array}$ & tidak ada & \begin{tabular}{|l|} 
sangat \\
terpengaruh
\end{tabular} & $\begin{array}{l}\text { Tidak } \\
\text { /tinggi }\end{array}$ \\
\hline $\begin{array}{l}=\text { jumlah } \\
\text { pinjaman }\end{array}$ & $\begin{array}{l}>3 \\
\text { tahun }\end{array}$ & tidak ada & \begin{tabular}{|l} 
tidak \\
terpengaruh
\end{tabular} & $\begin{array}{l}\text { Ya / } \\
\text { rendah }\end{array}$ \\
\hline $\begin{array}{l}=\text { jumlah } \\
\text { pinjaman }\end{array}$ & $\begin{array}{l}>3 \\
\text { tahun }\end{array}$ & tidak ada & \begin{tabular}{|l} 
tidak \\
terpengaruh
\end{tabular} & $\begin{array}{l}\text { Ya / } \\
\text { rendah }\end{array}$ \\
\hline $\begin{array}{l}<\text { jumlah } \\
\text { pinjaman }\end{array}$ & $\begin{array}{l}1-3 \\
\text { tahun }\end{array}$ & tidak ada & \begin{tabular}{|l} 
tidak \\
terpengaruh
\end{tabular} & $\begin{array}{l}\text { Tidak } \\
\text { /tinggi } \\
\end{array}$ \\
\hline
\end{tabular}

Dimana :

$S=30 \quad S 1=19 \quad S 2=11$

Keterangan :

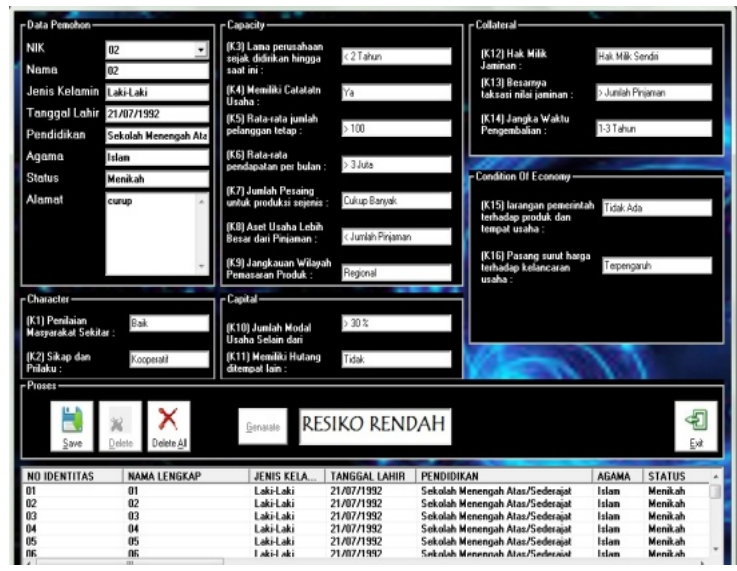

Gambar 3. Menu Proses

$S \quad$ = jumlah himpunan kasus

$S 1$ = jumlah keputusan rendah

$S 2$ = jumlah keputusan tinggi

Cara kerja menu proses yaitu penyaringan data dengan pohon keputusan yang telah dirancang menggunakan rumus algoritma C4.5 dengan menghitung nilai entropy dan gain tertinggi dari tabel data survey yaitu database history dari pemohon yang telah pernah mengajukan di BRI dimana gain tertinggi pertama sebagai akar utama dan entropy dan gain tertinggi kedua sebagai akar kedua dan seterusnya. Kemudian pohon keputusan tersebut diterapkan kedalam sistem aplikasi yaitu pada menu proses dalam bentuk aturan IF and Then.

Tampilan laporan hasil klasifikasi menggunakan algoritma C4.5 seperti Gambar 4 dibawah ini.

\section{Melayani Dengan Setulus Hati}

Gambar 2. Menu Utama

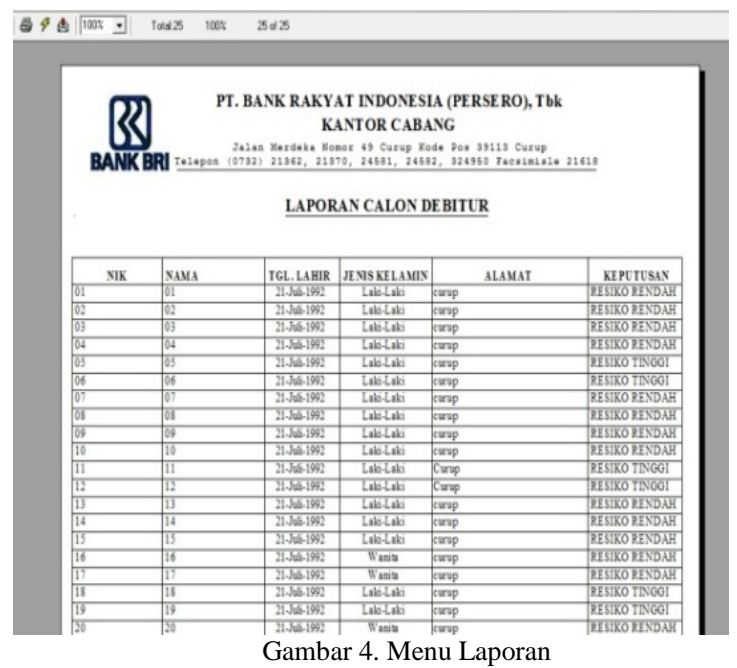




\subsection{Pengujian Sistem}

Pengujian sistem menggunakan metode

black box dan mendapatkan hasil sebagai berikut:

\begin{tabular}{|c|c|c|c|}
\hline $\begin{array}{c}\text { Proses } \\
\text { yang } \\
\text { diuji }\end{array}$ & $\begin{array}{c}\text { Skenario } \\
\text { Pengujian }\end{array}$ & $\begin{array}{l}\text { Hasil yang } \\
\text { diharapkan }\end{array}$ & $\begin{array}{c}\text { Hasil } \\
\text { Pengujian }\end{array}$ \\
\hline $\begin{array}{l}\text { Menu } \\
\text { Login }\end{array}$ & $\begin{array}{l}\text { 1. Nama benar } \\
\text { sedangkan } \\
\text { password } \\
\text { salah } \\
\text { 2. Password } \\
\text { benar } \\
\text { sedangkan } \\
\text { Nama Salah } \\
\text { 3. Nama dan } \\
\text { password } \\
\text { benar }\end{array}$ & $\begin{array}{l}\text { Akan muncul } \\
\text { pemberitahuan } \\
\text { password salah } \\
\text { Akan muncul } \\
\text { pemberitahuan } \\
\text { nama salah } \\
\text { Akan tampil } \\
\text { menu utama }\end{array}$ & $\begin{array}{l}\text { Sesuai } \\
\text { yang } \\
\text { diharapkan }\end{array}$ \\
\hline $\begin{array}{l}\text { Menu } \\
\text { Utama }\end{array}$ & $\begin{array}{l}\text { Memiliki lima } \\
\text { menu, yaitu } \\
\text { File, laporan, } \\
\text { petunjuk, } \\
\text { Tentang, dan } \\
\text { keluar }\end{array}$ & $\begin{array}{l}\text { Setiap menu } \\
\text { memiliki } \\
\text { submenu, dan } \\
\text { setiap submenu } \\
\text { akan tampil form } \\
\text { yang diinginkan }\end{array}$ & $\begin{array}{l}\text { Sesuai } \\
\text { yang } \\
\text { diharapkan }\end{array}$ \\
\hline $\begin{array}{l}\text { Input } \\
\text { data }\end{array}$ & $\begin{array}{l}\text { 1. Tombol } \\
\text { tambahakan } \\
\text { membuat } \\
\text { data baru } \\
\text { 2. Tombol } \\
\text { simpan akan } \\
\text { menyimpan } \\
\text { data } \\
\text { 3. Tombol } \\
\text { koreksi akan } \\
\text { mengubah } \\
\text { data } \\
\text { 4. Tombol } \\
\text { delete akan } \\
\text { menghapus } \\
\text { data } \\
\text { 5. Tombol } \\
\text { keluar akan } \\
\text { kembali ke } \\
\text { menu utama }\end{array}$ & $\begin{array}{l}\text { 1. Data baru akan } \\
\text { bertambah } \\
\text { 2. Data akan } \\
\text { tersimpan } \\
\text { 3. Data bisa } \\
\text { diubah dan } \\
\text { disimpan } \\
\text { 4. Data akan } \\
\text { dihapus akan } \\
\text { menampilkan } \\
\text { menu utama }\end{array}$ & $\begin{array}{l}\text { Sesuai } \\
\text { yang } \\
\text { diharapkan }\end{array}$ \\
\hline Proses & $\begin{array}{l}\text { Menjawab } \\
\text { semua } \\
\text { pertanyaan yang } \\
\text { diberikan oleh } \\
\text { sistem tentang } \\
\text { penyaringan } \\
\text { data dengan } \\
\text { pohon } \\
\text { keputusan } \\
\text { algoritma C4.5 }\end{array}$ & $\begin{array}{l}\text { Akan } \\
\text { memberikan hasil } \\
\text { keterangan } \\
\text { tingkat risiko } \\
\text { calon debitur }\end{array}$ & $\begin{array}{l}\text { Sesuai } \\
\text { yang } \\
\text { diharapkan }\end{array}$ \\
\hline Laporan & $\begin{array}{l}\text { Melihat hasil } \\
\text { laporan dari } \\
\text { proses C4.5 }\end{array}$ & $\begin{array}{l}\text { Akan } \\
\text { menampilkan } \\
\text { laporan hasil }\end{array}$ & $\begin{array}{l}\text { Sesuai } \\
\text { yang } \\
\text { diharapkan }\end{array}$ \\
\hline
\end{tabular}

\section{PENUTUP}

Berdasarkan hasil pembahasan dan pengujian dapat diambil kesimpulan sebagai berikut :

1. Data yang diperoleh merupakan data pemohon calon debitur Bank Rakyat Indonesia Kantor Cabang Curup, dimana aplikasi sistem pendukung keputusan sangat membantu pengambilan keputusan untuk menghindari kredit macet secara dini berdasarkan kriteria 5C.

2. Dari data 25 pemohon yang baru mengajukan terdapat tujuh pemohon yang berisiko tinggi yaitu nasabah macet kredit dan delapan belas pemohon yang berisiko rendah yaitu dapat diterima sebagai nasabah debiitur Bank Rakyat Indonesia Kantor Cabang Curup.

3. Dari hasil pengujian sistem maka diperoleh jawaban Sangat Menarik 57,5\%, Menarik 32,5\%, dan Tidak Menarik 10\% dari 20 responden yang dimintai keterangan.

Dari penelitian ini masih banyak terdapat kemungkinan untuk mengembangkan atau meningkatkan kemampuan, serta menutupi kekurangan-kekurangan yang telah dipaparkan diatas, beberapa hal yang disarankan peneliti pengembangan aplikasi ini agar lebih maksimal.

1. Diharapkan aplikasi ini dapat dikembangkan untuk bisa diakses secara online agar dapat digunakan dimana dan kapan saja sebagai media informasi teknologi khususnya tentang penentuan tingkat risiko calon debitur Bank Rakyat Indonesia.

2. Diharapkan aplikasi ini dapat dikembangkan untuk bisa digunakan di mobile phone seperti: Android atau smartphone. 
Jurnal Pseudocode, Volume III Nomor 2, September 2016, ISSN 2355-5920

\section{REFERENSI}

[1] Y. Ma, 2010, Research of SVM Applying in the Risk of Bank’s Loan to Enterprises, no. 3, pp. 1-5, America.

[2] D. Zhang, H. Hu, and H. Zhang, 2011, Risk Analysis of Credit Rating Business for Commercial Banks on Small and Medium-sized Enterprise, in 2011 InternationaL Conference on Information Management, Innovation Management and Industrial Engineering, pp. 312-315.

[3] Y. Jiang and L. H. Wu, 2009, Credit Scoring Model Based on Simple Naive Bayesian Classifier and a Rough Set, IEEE, pp. 1-4.

[4] Kusrini \&Luthfi, Emha Taufiq, 2009, Algoritma Data Mining. Penerbit C.V Andi Offset (Penerbit Andi). Yogyakarta.

[5] X. Y. Yu and A. Wang, 2010, Genetic Algorithm Based Bayesian Network for Customers Behavior Analysis, Sixth International Conference on Intelligent Information Hiding and Multimedia Signal Processing, pp. 406-409.

[6] J. Han and M. Kamber, 2006, Data Mining Concept and Technique, Second Edi. Morgan Kaufmann Publisher, Amsterdam.
[7] Undang-Undang Republik Indonesia No 10, 1998.

[8] Rifqo, M.H., 2012, Penentuan Kelayakan Pemberian Kredit Mobil dengan Menggunakan Naive Bayes dan Particle Swarm Optimization (PSO), Semarang. 